\title{
Simulated Interprofessional Education Program For Training Clinical Critical Thinking In Medical Nursing Students: A Mixed Method Study
}

\author{
Xin-yi Zhou \\ Jinan University \\ Yan-feng Wang \\ Jinan University \\ Chun-xia Dou \\ Jinan University \\ Xiao-ying Tian \\ Jinan University \\ Jin Su \\ Jinan University \\ Yan-ya Chen \\ Jinan University \\ Feng-xia Yan \\ Jinan University \\ Qiao-hong Yang ( $\nabla$ yqiaohong@163.com ) \\ Jinan University \\ Wenru Wang \\ National University of Singapore
}

\section{Research Article}

Keywords: Simulated interprofessional education, Interprofessional cooperation, Critical thinking, Medical nursing students

Posted Date: March 7th, 2022

DOI: https://doi.org/10.21203/rs.3.rs-1408417/v1

License: (c) (i) This work is licensed under a Creative Commons Attribution 4.0 International License.

Read Full License 


\section{Abstract}

Background: Simulation teaching, which cultivates cooperation and communication in the interprofessional team, has become a suitable type of interprofessional cooperation in college students' health professional courses. This study aimed to explore the intervention effect of simulated interprofessional education (SIPE) on clinical critical thinking of medical nursing students.

Methods: This study was a mixed method research including quantitative and qualitative assessment.

Results: A total of 30 medical nursing students were randomly divided into a control group (18) and an experimental group (12). The mean scores on interprofessional cooperation and critical thinking of the experimental group were higher than those of the control group $(P<0.05)$. Quantitative evaluation was conducted using a scale, and qualitative evaluation was conducted through semi-structured interviews. There were three themes emerged: clarifying team positioning, improving team effectiveness, and optimizing the learning experience.

Conclusion: This study found that the SIPE program improved medical nursing students' ability to work in interprofessional teams.

\section{Background}

The health care system represents an integration because rehabilitation of patients cannot be separated from the need for cooperation among the various health care disciplines. Collaborative care is considered the gold standard of the health care model, aiming to give patients the best help through interdisciplinary collaboration [1]. However, current medical personnel training is mainly based on the single training mode, with independent cultivation and a lack of cooperation between the various disciplines and specialties [2]. Isolation in professional training does not meet the current demand for both professional role recognition. Receiving interprofessional education helps students to better play a role in team collaboration [3]. Interprofessional education refers to how two or more professionals understand, learn, and cooperate in improving patients' health outcomes [4]. Studies have shown that interprofessional education can strengthen collaborative learning, enhance patient care quality [5], shorten patients' inhospital time, and increase medication safety [6].

Simulation teaching [7] provides learners with an immersive and realistic teaching mode to help nursing students learn and develop good critical thinking ability [4]. In addition, this method can also meet the need for repeated teaching so that students can find mistakes and learn from experience $[4,8]$. We also recognize patients' complex conditions and the increasing diversity of diseases resulting from changes in the disease spectrum. At present, there are still many challenges in cultivating students' critical thinking, that is, to adopt the best response measures through interpretation, analysis, evaluation, and inference [9]. 
In recent years, simulation teaching, which cultivates cooperation and communication in the interprofessional team, has become a suitable type of interprofessional cooperation in college students' health professional courses [10]. Integrating simulated teaching and interprofessional education enable simulated interprofessional education (SIPE) mode [11]. Studies have shown that this model can cultivate students' teamwork ability, increase their understanding of other professional roles, cultivate inter-specialty communication skills, and improve their confidence in simulated cooperative situations. It can also engage the learned knowledge, skills, and values in future collaborative practices [12]. However, because of various factors, this model is mainly carried out in the United States, Europe, and other Western countries. In contrast, its application in China and other Asian countries is not sufficient [10]. Most roles of physicians and pharmacists in simulation practice courses are mainly played by nursing students directly, which fails to achieve real interprofessional simulation.

Due to the limitations of a single primary training mode, the cultivation of team communication and cooperation ability among medical students in various majors is lacking. It is urgent to introduce innovative education methods to guarantee the education level and meet the need for cultivating highquality medical and health talents [13]. Based on the theoretical framework of the Biggs' 3P model [14], this study explored the application of the SIPE model in the "clinical critical thinking training" course of nursing in China, providing a reference for the reform of medical education and a talent cultivation model.

\section{Methods}

\section{Design}

This study was a mixed method research including quantitative and qualitative assessment. This study was obtained the ethical approval from the Ethics Committee of XXX.

\section{Participants}

Cluster sampling was used to select 30 full-time grade 3 students majoring in nursing at a nursing school. The students had completed nursing foundation, health assessment, and nursing courses in various specialties. The students were randomly divided into a control group and an experimental group. Based on the principle of voluntary participation, three grade 2 clinical medicine major students and three students with a grade 3 pharmacy major were also recruited into the experimental group.

\section{Study Intervention}

"Clinical Critical Thinking Training" is the core nursing course in our hospital, with 2 credits, including 28 hours of theoretical courses and 20 hours of experimental courses, totaling 48 hours. Experimental classes are 4 hours per class, once a week, for 5 consecutive weeks with simulated cases designed by instructors from the nursing, clinical medicine, and pharmacy departments. Case scenarios focused on 
patients in gynecology, pediatrics, and intensive care units. The same teaching materials, simulation cases, and instructors were used in the two groups. Students in each group were randomly divided into three teams, with six members in each team, including one physician, one responsible nurse, one auxiliary nurse, one clinical pharmacist, one patient family member, and one observer. The responsible nurse was the team leader, responsible for the organization, coordination, division of labor, and cooperation within the team. The control group used conventional simulation teaching, in which nursing students acted as the physicians and clinical pharmacists involved in the case. The experimental group adopted SIPE, and each team had one student majoring in clinical medicine and one student majoring in pharmacy.

Using Biggs's 3P model as the theoretical framework, this course practice was divided into "presage, process, and product." The problem-based learning (PBL) method was used to cultivate students' clinical critical thinking, team communication, and cooperation abilities. In the first experimental course, teams became acquainted through team training, and faculty introduced the experimental course. For the three experimental classes in the middle, instructors prepared three scenarios following the gynecology, pediatrics, and intensive care units. The teachers of the three experimental classes in the middle prepared three scenarios in order according to the adult department, the gynecology and pediatrics department, and the intensive care unit, and released them to the students on the teaching platform in advance. The faculty introduced these scenarios for students on the teaching platform in advance. Each team could discuss the cases in advance. For the last experimental class, the instructor prepared three scenarios at the same time but did not introduce them in advance. Three teams drew lots to simulate the demonstration. The SIPE program design framework is shown in Fig. 1.

Insert Fig. 1 here.

Figure 1. The flowchart of simulated interprofessional education program. This curriculum was designed based on the theoretical framework of the Biggs's 3P model, which included three steps as "presage, process, and product."

Preparation for learning was divided into introductory and implementation parts. Introductory preparation was carried out in the first experimental class, which mainly introduced the experimental course objective, content, and arrangement, team structure, and the importance of team cooperation. The case analysis and the discussion of the four cores of team cooperation (leadership, effective communication, mutual support, and situation monitoring) were used to improve students' understanding of the team and strengthen students' sense of team. Through the paper chain game, the length of the paper chain made by each team is compared, and the team cooperation is simulated, so that students can understand the importance of the close connection and effective cooperation of the medical team.

Before the last four experimental classes, implementation preparation was carried out, including instructor and student preparation. The interprofessional teaching team comprises one instructor from clinical medicine, one instructor from nursing, and one instructor from the pharmacy who jointly formulated teaching objectives, determined simulated cases, set situational questions, and issued cases and tasks through the teaching platform. Instructors in the experimental center were responsible for the 
layout of simulated case scenarios, providing instruments and equipment commonly used in treatment and nursing, and setting the conditions of the SimMan $3 \mathrm{G}$ high simulation person according to the case. Students needed to be familiar with the theoretical knowledge and operational skills related to the case and to discuss the case within the team.

\section{Study Process}

Each case was set up as a "three-station" simulation scenario, namely, the health assessment at admission, the evaluation of the implementation of the diagnosis and treatment plan, and the health guidance at discharge. Each scenario included 5-10 minutes of preparation before the simulation and 15-20 minutes of case simulation. According to the requirements of scenario simulation, the time ratio between simulation and guiding feedback is $1: 2$ or 1:3 [15], and so feedback took place for $30-40$ minutes. According to case scenarios and situational problems, team members made an overall assessment of the patients according to their professional focus, shared the assessment results, and jointly formulated examination, treatment, and nursing plans. All students should closely observe the changes in the patient's condition, communicate in a timely manner, and cooperate with team members. Also, they need to comprehensively use the theoretical knowledge and techniques that they have mastered to ensure the correct response and treatment to promote the recovery of patients. The whole simulation process is recorded, and the instructor does not give any hints but can adjust the situation randomly according to the simulation.

At the end of each simulation, the instructor used three steps to guide the students to review and reflect. First, the students were asked about the experience of the simulation teaching so that the students could fully express and share their emotions. Second, the students watched a video, focusing on the key scenarios, and were asked open questions, such as "What do you think what happened," "How did you think of," "What will you do next time". This helped students to think about the causes, effects, and shortcomings of their behavior and mutually evaluate the performance of each role in the team. Third, students were helped to summarize their learning experience by reviewing key learning points and asking questions about relevant knowledge in simulation scenarios. Later, the instructor evaluated students' personal performance and the team's overall performance, focusing on clinical critical thinking and team communication and cooperation, and looking at the nursing specialty students' cognitive skills, emotional attitudes, communication strategies, and cooperative attitudes. This study aimed to evaluate whether the condition-based correct nursing diagnosis and nursing measures were put forward, whether students thought independently, and whether their communication was effective. Also, we wanted to analyze the application of communication skills and whether the team reached consensus and mutual support. Finally, the instructors pointed out the strengths and weaknesses of students' performance and offered suggestions for improvement.

\section{Evolution Methods}


This study used a quantitative survey and a qualitative interview for evaluation. The California Critical Thinking Disposition Inventory (CCTDI) [16] and Assessment of Interprofessional Team Collaboration in Student Learning Scale (AITCS-II student) [17] were used to assess the experimental and control groups before and after the experiment. Qualitative evaluation uses semi-structured interviews to obtain information on students' participation experience and is conducted after the course.

\section{Self-assessment methods}

The California Critical Thinking Disposition Inventory (CCTDI): The Scale was developed by Facione et al. [16]. The characteristics of seven aspects of critical thinking are measured: truth-seeking, openmindedness, systematicity, self-confidence, inquisitiveness, maturity, and analyticity. In China, there is Chinese version of the CCTDI with a total of 70 items [18], and a 6-point Likert scale is used, ranging from 1 (strongly agree) to 6 (strongly disagree), with a total score of $70-420$. The higher the score, the stronger the critical thinking. A score of 40 or more indicates an upbeat personality on that scale; a total score of 280 or above shows positive general critical thinking tendencies. The total content validity index (CVI) and Cronbach's a coefficient of the scale were 0.89 and 0.90 .

Assessment of Interprofessional Team Collaboration in Student Learning Scale (AITCS-II Student): The Scale was developed by Orchard et al. [17] based on the first version of the Assessment of Interprofessional Team Collaboration Scale (AITCS). The Likert grade 5 scoring method was adopted: "never" = 1, "rarely" = 2, "occasionally" = 3, "most of the time" = 4, "always" = 5. Cronbach's a coefficient of the scale was 0.961 , and the Cronbach's a coefficient of each dimension was 0.719-0.938. The scale's total score was $16-80$, and the mean score was $\geq 4$, indicating good cross-major cooperative learning ability [19].

\section{Semi-Structured Interviews}

After the course, the students' experience of participating in the course was investigated through semistructured interviews. The teaching effect was evaluated in multiple ways and from various angles. According to the students' performance in the guided feedback session, six suitable interviewees were selected.

Interprofessional Education Collaborative [20] outlines interprofessional core competencies in five themes: roles and responsibilities, ethical practice, conflict resolution, communication, collaboration, and teamwork, and states that one or more themes should be considered when designing interprofessional activities. We formulated an interview outline based on these situations: (1) How do you view each role within the team and its responsibilities? (2) Do you believe you are meeting the standard of professional practice expected of your role and fulfilling its responsibilities? (3) Have you encountered disagreements in achieving your team's work goals? If so, how was it resolved? (4) Talk about your response to the course, such as your gains, lack of interprofessional case design, and suggestions for course improvement. 


\section{Data analysis}

The scale data were entered using EpiData3.1 software, and SPSS 26.0 software was used for t-test analysis, and the test level was $a=0.05$. Semi-structured interviews used thematic analysis to process data.

\section{Results}

\section{Before and After CCTDI and AITCS-II Student Results}

The mean scores of critical thinking and interprofessional cooperation before and after the experiment are shown in Table 1. Before the experiment, no significant differences were found in critical thinking and inter-professional cooperation between the control and experimental groups. Critical thinking and interprofessional cooperation in the experimental group were significantly higher than in the control group after the experiment $(P<0.05)$.

Table 1

Comparison of mean scores of AITCS-II and CCTDI between control and experimental groups at baseline and post-intervention

\begin{tabular}{|c|c|c|c|c|c|c|c|c|}
\hline \multicolumn{3}{|c|}{ CCTDI } & \multirow[t]{2}{*}{$t$} & \multirow[t]{2}{*}{$P$} & \multicolumn{2}{|c|}{ AITCS-II Student } & \multirow[t]{2}{*}{$\mathrm{t}$} & \multirow[t]{2}{*}{$P$} \\
\hline & Control & Experimental & & & Control & Experimental & & \\
\hline Pre & $\begin{array}{l}235.61 \pm \\
34.07\end{array}$ & $\begin{array}{l}236.22 \pm \\
29.83\end{array}$ & 0.06 & 0.95 & $\begin{array}{l}3.63 \pm \\
0.41\end{array}$ & $3.82 \pm 0.31$ & 1.59 & 0.12 \\
\hline Post & $\begin{array}{l}244.61 \pm \\
31.53\end{array}$ & $\begin{array}{l}285.06 \pm \\
15.26\end{array}$ & 4.90 & $\hat{0}_{0.01}$ & $\begin{array}{l}3.64 \pm \\
0.45\end{array}$ & $4.04 \pm 0.33$ & 3.09 & $\begin{array}{l}< \\
0.01\end{array}$ \\
\hline
\end{tabular}

Insert Table 1 here.

\section{Post-Experiment CCTDI Student Results}

The scores on each subscale of critical thinking in the control and experimental groups after the experiment are shown in Table 2. In general, the students' critical thinking in the experimental group was higher than that of the students in the control group, and the difference was statistically significant. However, there was no statistically significant difference between the scores on systematic ability in the critical thinking scale and the control group $(P>0.05)$. 
Table 2

Post-experiment CCTDI Student Results

\begin{tabular}{|c|c|c|c|c|}
\hline & Control group & Experimental group & \multirow[t]{2}{*}{$\mathbf{t}$} & \multirow[t]{2}{*}{$\mathbf{P}$} \\
\hline & Mean \pm SD & Mean \pm SD & & \\
\hline CCTDI(Total) & $244.61 \pm 31.53$ & $285.06 \pm 15.26$ & 4.90 & $0.000^{\star \star \star}$ \\
\hline Truth-seeking & $35.50 \pm 7.29$ & $39.56 \pm 3.81$ & 2.09 & $0.047^{*}$ \\
\hline Openmindedness & $37.83 \pm 6.17$ & $42.72 \pm 2.63$ & 3.09 & $0.005^{\star \star}$ \\
\hline Systematicity & $39.44 \pm 7.35$ & $41.94 \pm 5.18$ & 1.18 & 0.247 \\
\hline Self-confidence & $29.72 \pm 4.51$ & $38.56 \pm 3.80$ & 6.36 & $0.000^{\star \star \star}$ \\
\hline Inquisitiveness & $32.11 \pm 5.52$ & $38.11 \pm 4.61$ & 3.54 & $0.001^{* \star}$ \\
\hline Maturity & $39.17 \pm 8.30$ & $44.50 \pm 3.38$ & 2.52 & $0.019^{*}$ \\
\hline Analyticity & $31.83 \pm 5.47$ & $38.67 \pm 3.93$ & 4.31 & $0.000^{\star \star \star}$ \\
\hline \multicolumn{5}{|c|}{${ }^{\star} p<0.05,{ }^{* *} p<0.01,{ }^{* \star \star} p<0.001$} \\
\hline
\end{tabular}

Insert Table 2 here.

\section{Semi-Structured Interviews}

In total six interviewees were selected for these interviews, all of whom were nursing majors, including three in the experimental group and three in the control group. The interview results were summarized into three themes and two recommendations.

\section{Three themes}

(1) Interprofessional combination can clarify role positioning: The feedback results showed that the roles of the members in the interprofessional portfolio team are clear, and they could perform their roles and responsibilities better by adhering to professional practice standards. Students from inter-professional teams said "I feel that the professional competencies required for each role have been met," and "I can find my position and make a difference." However, students in the same professional combination said: "Although I am playing Doctor, sometimes I still work as a nurse," "I can't give professional advice."

(2) Interprofessional combination can improve team effectiveness: In interviews, students reported that interprofessional teams were more effective. Students from the inter-professional combination said: "We work well together," "We can deal with it quickly," "Everyone is very professional, and the advice given is convincing." However, students from the same professional combination said: "Our cooperation is not working well," "Sometimes we can't persuade each other, so I choose to compromise." 
(3) Interprofessional combination can enhance the learning experience: When talking about their learning experiences and feelings, the students in the inter-professional combination gave more positive feedback. They believed that "It is more interesting to cooperate with students from other majors in the classroom." Students expressed that "I feel that this form is very novel, and I will try my best to make myself do better," and "I hope that other courses can also apply inter-professional teaching methods in the future." However, students in the same professional combination said, "I feel powerless when I play the role of a doctor," and "I hope to adopt an inter-professional education method."

\section{Two Suggestions}

(1) Extend the time of the laboratory class: When asked about their ideas for improving the curriculum, the students wanted to extend the class hours and increase the number of simulated practice sessions. They said, "I feel that five experimental classes are a little short." Some said "If time permits, I hope that each scene can be simulated twice." "Because the first experimental class is the introduction to the course, the actual experimental training is only four times, which feels a bit less, so I hope that the number of times of experimental training can be increased."

(2) Simulated case scenarios should increase emergency department and community involvement: In the simulation scenarios, the students expressed the hope of adding emergency departments and community hospitals to further improve their clinical critical thinking and teamwork ability to meet the practical needs of different scenarios. Their answers included "I think the emergency department has an important position in the hospital department and should be included," and "The emergency department has higher requirements for the independent judgment and problem-solving ability of medical staff, and I would hope to add this department." Other opinions were "The country is currently vigorously developing community medical services, and community medical talents are also crucial, so I think this scene should be added," "I plan to work in a community hospital in the future and hope to have an exercise in this context," and "I think the hospital can increase the emphasis on emergency departments and outside the hospital can add to the community."

\section{Discussion}

Critical thinking ability should be used as a mandatory indicator to evaluate the quality of nursing education at undergraduate and higher levels [21]. The results of this study show that the critical thinking ability in the two groups of students improved after teaching. Except for systematic ability, the total score, and the scores of the other six dimensions in the experimental group were significantly higher than those in the control group (all $p<0.01$ ). This result is consistent with the findings of Xie et al. [22]: simulated interprofessional education has certain advantages for improving clinical critical thinking of medical students. Simulation-based interprofessional medical education provides medical students with a safe and controllable clinical environment that allows for trial and error, testing judgmental hypotheses, and repeated practice exercises to expand clinical critical thinking. Three representative departments were examined in this study, which could effectively improve the analytical ability of nursing students in different situations and enhance their self-confidence in applying critical thinking. The lack of statistical 
significance in the dimension of systematization ability between the two groups may be due to insufficient intervention time. The teaching time will be increased in the future to study the effect of this teaching method on improving systematization ability.

This study found that the interprofessional cooperative learning score in the experimental group was higher than that of the control group. This result indicates that the interprofessional cooperative team established an excellent cooperative partnership, improved interprofessional cooperative learning ability, and actively coordinated and communicated to achieve teamwork goals, which are consistent with relevant research results $[23,24]$. At present, the working mode of medical and nursing integration is being widely explored and applied in clinical practice. The integration of medical and nursing [25] occurs through joint planning, joint decision-making, joint goal-setting and problem-solving, and joint responsibility for patients through the cooperation of medicine and nursing. It requires mutual trust and respect on behalf of both parties.

Poor medical communication and teamwork are important factors hindering the integration of medical care and affecting the quality and safety of nursing and adverse events. Poor communication between physicians and nurses and poor teamwork are important factors that hinder the integration of medical care and affect the quality and safety of nursing care and adverse events [26]. This study established interprofessional learning teams to address the problems of low self-efficacy and low confidence in simulation practice with role-playing by a single professional. On the one hand, it increased students' interest in learning, and on the other hand, it mobilized students' subjective initiative and jointly promoted the realization of team goals. This is conducive to establishing a relationship of mutual trust and respect between physicians and nurses in actual clinical practice in the future and promotes the development of an integrated medical and nursing work model.

Role ambiguity puts team members at risk of conflict, team dysfunction, and burnout [20]. The low team effectiveness in the control group in this study may have occurred because some team members played interprofessional roles. They may have lacked the professional ability and quality that matched their role and may have been limited by their actual professional thinking, making their role orientation ambiguous. When they encountered differences of opinion, they failed to give constructive opinions that fit their roles, causing other members to burn out. Finally, they chose a compromise method to help the team to reach a consensus. The interprofessional team structure of the experimental group made up for this deficiency and improved team effectiveness.

Communication is a central concept in much interprofessional education and teaching. Effective communication promotes teamwork, and poor information transfer in medical practice is closely related to potential harm to patients and ultimately affects patient outcomes [27, 28]. The role-playing experience in the experimental group was better than that of control group, probably because of higher team effectiveness. The operating mode of the experimental group was closer to the integration of medical care and nursing. This group was responsible for overall care of the patients, could timely and accurately perceive the needs of the patients, and apply corresponding treatments to achieve the teamwork goals 
faster and better. Communication plays a vital role in this. On the other hand, the control group communicated poorly, and took about twice as long to achieve the same effect. In addition, highperforming teams can increase team members' self-confidence and enthusiasm for work, making them more confident in solving problems.

In response to the suggestion from students for adding emergency department scenarios to the case, this study considers the emergency departments' high requirements for clinical critical thinking and teamwork ability when formulating the teaching design. Because of the limitation of class hours, it may be difficult for students to achieve corresponding ability requirements, so there was no separate emergency department scenario case. In the fifth week of the course, the instructor did not announce the case in advance and conducted a simulation demonstration by drawing lots on the spot to simulate a sudden scene as much as possible. The instructor did not consider that students wanted to add a community hospital scene to the case when designing the simulation case. In the future, through curriculum reform, the number of experimental courses will be increased, and more cases in scenarios will be available for simulation and demonstration.

\section{Study Limitations}

There are some limitations in this study. First, this study explored only the application of a specific course in one school. The model should be applied to multiple courses in the future to expand the scope for applying simulated interprofessional teaching. Second, this study used scales based on the perspective of the students, and there may be bias in self-evaluation. In the future, different methods can be used to evaluate the teaching effect from multiple perspectives and continuously to further verify the stability of the teaching model.

\section{Study Implications}

The findings of this study provide a basis for collaborative learning among various medical specialties, cover the insufficiency of real-situational experiential learning, and complement the limitations of medical students in clinical practice. Innovative education methods are needed to guarantee the education levels and meet the needs of cultivating high-quality medical and health talents.

\section{Conclusion}

This exploratory study was conducted by applying Biggs' 3P model to design a simulated interprofessional educational course and to verify the feasibility and effectiveness of the formulated educational strategy. This study found that it is feasible and effective to adopt the scientifically designed simulated interprofessional education model in practical teaching, thereby improving students' critical thinking ability and teamwork ability and promoting communication and cooperation among medical specialties in teaching courses. 


\section{Declarations}

Ethics approval and consent to participate: All methods were carried out in accordance with the Declaration of Helsinki. All experimental protocols were approved by the Institutional Review Board of Jinan University (approval number: JNUKY-2021-014). Informed consents were obtained from all participants.

Consent for publication: Not applicable in the declarations section.

Availability of data and materials: The datasets generated and analysed during the current study are not publicly available due we may have further research related to the data but are available from the corresponding author on reasonable request.

Competing interests: The authors have no conflicts of interest to declare.

Funding: This work was supported by research project of higher education teaching method reform of Guangdong Province in 2019 and the 22rd research project of teaching method reform of Jinan University.

\section{Authors' contributions:}

1. Qiao-hong Yang: Conceptualization, Methodology, Validation, Resources, Investigation, Formal analysis, Writing - Original Draft, Writing - Review \& Editing, Supervision, Project administration, Funding acquisition.

2. Wenru Wang: Conceptualization, Methodology, Writing - Review \& Editing.

3. Feng-xia Yan: Resources, Investigation, Formal analysis, Supervision, Project administration.

4. Xin-yi Zhou: Conceptualization, Methodology, Validation, Resources, Investigation, Writing - Original Draft, Writing - Review \& Editing, Visualization.

5. Yan-feng Wang: Methodology, Resources, Investigation, Formal analysis, Writing - Review \& Editing, Visualization.

6. Chun-xia Dou: Resources, Writing - Review \& Editing, Formal analysis, Project administration.

7. Xiao-ying Tian: Investigation, Project administration.

8. Jin Su: Writing - Review \& Editing.

9. Yan-ya Chen: Resources, Investigation, Formal analysis.

Acknowledgements: We would like to thank all participants, contributing authors, and peer reviewers for their precious opinions and suggestions." 


\section{Ethical Approval}

This study was obtained the ethical approval from the Ethics Committee of Jinan University (\#JNUKY2021-014).

\section{Acknowledgements}

The authors would like to thank all the teachers and students involved in this study.

\section{Funding}

This work was supported by research project of higher education teaching method reform of Guangdong Province in 2019 and the $22^{\text {rd }}$ research project of teaching method reform of Jinan University.

\section{Declarations of Interest}

None.

\section{References}

1. Reed, K., Reed, B., Bailey, J., Beattie, K., Lynch, E., Thompson, J.,.. . Wilson, R. (2021). Interprofessional education in the rural environment to enhance multidisciplinary care in future practice: Breaking down silos in tertiary health education. Australian Journal of Rural Health, 29(2), 127-136. https://doi.org/10.1111/ajr.12733

2. Son, H. K. (2021). The effects of simulation problem-based learning on the empathy, attitudes toward caring for the elderly, and team efficacy of undergraduate health profession students. International Journal of Environmental Research and Public Health, 18(18). https://doi.org/10.3390/ijerph18189658

3. Buring, S. M., Bhushan, A., Broeseker, A., Conway, S., Duncan-Hewitt, W., Hansen, L., \& Westberg, S. (2009). Interprofessional education: definitions, student competencies, and guidelines for implementation. American Journal of Pharmacy Education, 73(4), 59. https://doi.org/10.5688/aj730459

4. Kaddoura, M. A. (2010). New graduate nurses' perceptions of the effects of clinical simulation on their critical thinking, learning, and confidence. Journal of Continuing Education in Nursing, 41(11), 506-516. https://doi.org/10.3928/00220124-20100701-02

5. Sulaiman, N., Rishmawy, Y., Hussein, A., Saber-Ayad, M., Alzubaidi, H., Al Kawas, S.,.. . Guraya, S. Y. (2021). A mixed methods approach to determine the climate of interprofessional education among medical and health sciences students. BMC Medical Education, 21(1), 203. https://doi.org/10.1186/s12909-021-02645-4

6. Zwarenstein, M., Goldman, J., \& Reeves, S. (2009). Interprofessional collaboration: effects of practice-based interventions on professional practice and healthcare outcomes. Cochrane Database of Systematic Reviews (3), Cd000072. https://doi.org/10.1002/14651858.CD000072.pub2 
7. Villanueva, C., Xiong, J., \& Rajput, S. (2020). Simulation-based surgical education in cardiothoracic training. ANZ Journal of Surgery, 90(6), 978-983. https://doi.org/10.1111/ans.15593

8. Evgeniou, E., \& Loizou, P. (2013). Simulation-based surgical education. ANZ J Surg, 83(9), 619-623. https://doi.org/10.1111/j.1445-2197.2012.06315.x

9. Acosta, T., Sutton, J. M., \& Dotters-Katz, S. (2020). Improving learners' comfort with cesarean sections through the use of high-fidelity, low-cost simulation. MedEdPORTAL, 16, 10878. https://doi.org/10.15766/mep_2374-8265.10878

10. Lee, W., Kim, M., Kang, Y., Lee, Y. J., Kim, S. M., Lee, J.,.. . Park, Y. S. (2020). Nursing and medical students' perceptions of an interprofessional simulation-based education: A qualitative descriptive study. Korean Journal of Medical Education, 32(4), 317-327.

11. Tilley, C. P., Roitman, J., Zafra, K. P., \& Brennan, M. (2021). Real-time, simulation-enhanced interprofessional education in the care of older adults with multiple chronic comorbidities: A utilization-focused evaluation. Mhealth, 7, 3. https://doi.org/10.21037/mhealth-19-216

12. Labrague, L. J., McEnroe-Petitte, D. M., Fronda, D. C., \& Obeidat, A. A. (2018). Interprofessional simulation in undergraduate nursing program: An integrative review. Nurse Education Today, 67, 4655. https://doi.org/10.1016/j.nedt.2018.05.001.

13. Frenk, J., Chen, L., Bhutta, Z. A., Cohen, J., Crisp, N., Evans, T.,.. . Zurayk, H. (2010). Health professionals for a new century: transforming education to strengthen health systems in an interdependent world. Lancet, 376(9756), 1923-1958. https://doi.org/10.1016/s01406736(10)61854-5

14. Biggs, J. B. (1993). From Theory to Practice: A Cognitive Systems Approach. Higher Education Research \& Development, 12, 73-85.

15. Hu, L. P., Guo, A. M., Yang, H., Gu, R. R., \& Ma, Q. H. (2018). Application of multi-disciplinary cooperative situation simulation teaching in the clinical thinking training course for master of Nursing professional degree. Nursing Management in China, 18(07), 927-930.

16. Facione, P. A., Facione, N. C., \& Giancarlo, C. A. F. (2000). The California critical thinking disposition inventory: CCTDI test manual. California Academy Press.

17. Orchard, C. A., King, G. A., Khalili, H., \& Bezzina, M. B. (2012). Assessment of Interprofessional Team Collaboration Scale (AITCS): development and testing of the instrument. Journal of Continuing Education in the Health Professions, 32(1), 58-67. https://doi.org/10.1002/chp.21123

18. Peng, M. C., Wang, G. C., Chen, J. L., Chen, M. H., Bai, H. H., Li, S. G.,.. Yin, L. (2004). Research on reliability and validity of critical thinking ability measurement scale. Chinese Journal of Nursing (09), 7-10.

19. Shi, Y. W., Zhu, Z. F., \& Hu, Y. (2020). Sinicization and reliability and validity test of the Cross-major Cooperative Learning Assessment Scale (Student edition). Chinese Nursing Education, 17(05), 435438.

20. van Diggele, C., Roberts, C., Burgess, A., \& Mellis, C. (2020). Interprofessional education: tips for design and implementation. BMC Medical Education, 20(Suppl 2), 455. 
https://doi.org/10.1186/s12909-020-02286-z.

21. Wilgis, M., \& McConnell, J. (2008). Concept mapping: an educational strategy to improve graduate nurses' critical thinking skills during a hospital orientation program. Journal of Continuing Education in Nursing, 39(3), 119-126. https://doi.org/10.3928/00220124-20080301-12

22. Xie, B., Liu, B., Liu, F., \& Xu, X. L. (2012). The role of PBL teaching method in the cultivation of critical thinking ability of eight-year medical students in military academies. Higher Medical Education in China(3), 130-132.

23. Liu, Q., Ouyang, Y., Li, S. Y., Xu, J., Li, L., Xu, A. J., \& Zang, X. (2020). Application of interprofessional team cooperation simulation teaching in nursing planning and implementation experiment teaching. Journal of Nursing (China), 35(15), 69-71 + 91.

24. Zhuang, Q. L., Wang, T., \& Ye, J. F. (2021). Application of cross-specialty high simulation teaching in nursing comprehensive practice teaching. Journal of Nursing (China), 36(10), 83-84 + 88 .

25. Norful, A. A., de Jacq, K., Carlino, R., \& Poghosyan, L. (2018). Nurse practitioner-physician comanagement: a theoretical model to alleviate primary care strain. Annals of Family Medicine, 16(3), 250-256. https://doi.org/10.1370/afm.2230

26. Huang, H. Y., Wang, Y. F., Zhou, S., Wang, D., \& YU, L. N. (2018). Application of situational experience method in nursing adverse event prevention training for new nurses. Journal of Nursing (China), 33(01), 64-65.

27. Karam, M., Brault, I., Van Durme, T., \& Macq, J. (2018). Comparing interprofessional and interorganizational collaboration in healthcare: A systematic review of the qualitative research. Internationa Journal of Nursing Studies, 79, 70-83. https://doi.org/10.1016/j.ijnurstu.2017.11.002

28. Suter, E., Arndt, J., Arthur, N., Parboosingh, J., Taylor, E., \& Deutschlander, S. (2009). Role understanding and effective communication as core competencies for collaborative practice. Journal of Interprofessional Care, 23(1), 41-51. https://doi.org/10.1080/13561820802338579

\section{Figures}




Nursing students $\rightarrow \begin{gathered}\text { Control } \\ \text { group }\end{gathered}$

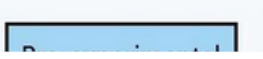

\section{Figure 1}

The flowchart of simulated interprofessional education program. This curriculum was designed based on the theoretical framework of the Biggs's 3P model, which included three steps as "presage, process, and product." 